\title{
Development Of A Fluorescent Anti-Factor Xa Assay To Monitor Unfractionated And Low Molecular Weight Heparins
}

\author{
Leanne Harris \\ Technological University Dublin, leanne.harris@tudublin.ie \\ Vanessa Castro-Lopez \\ Dublin City University \\ Nissrin Hammadi \\ Dublin City University
}

See next page for additional authors

Follow this and additional works at: https://arrow.tudublin.ie/scschbioart

Part of the Biology Commons

\section{Recommended Citation}

Killard, A. J. et al. (2010) Development Of A Fluorescent Anti-Factor Xa Assay To Monitor Unfractionated And Low Molecular Weight Heparins, Talanta,vol.81, iss. 4-5, June, 2010,p.1745-1730. doi:/10.1016/ j.talanta.2010.03.030

This Article is brought to you for free and open access by the School of Biological Sciences at ARROW@TU Dublin. It has been accepted for inclusion in Articles by an authorized administrator of ARROW@TU Dublin. For more information, please contact arrow.admin@tudublin.ie, aisling.coyne@tudublin.ie,gerard.connolly@tudublin.ie. Funder: Enterprise Ireland

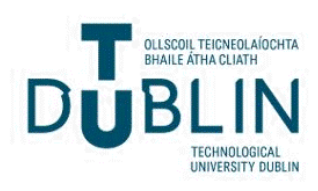




\section{Authors}

Leanne Harris, Vanessa Castro-Lopez, Nissrin Hammadi, James S. O'Donnell, and Tony Killard 
The development of a fluorescent anti-factor Xa (FXa) assay and its application to the monitoring of a range of heparin-like anticoagulants

Leanne F. Harris ${ }^{\mathrm{a}}$, Vanessa Castro-López ${ }^{\mathrm{a}}$, Nissrin Hammadi ${ }^{\mathrm{a}}$, James S. O’Donnella,b, Anthony J. Killard ${ }^{\mathrm{a}}$

${ }^{a}$ Biomedical Diagnostics Institute, National Centre for Sensor Research, Dublin City University, Dublin 9, Ireland.

${ }^{\mathrm{b}}$ Haemostasis Research Group, Trinity College Dublin, and National Centre for Hereditary Coagulation Disorders, St. James's Hospital, Dublin 8, Ireland.

Corresponding Author: Dr. Anthony J. Killard.

Biomedical Diagnostics Institute, National Centre for Sensor Research, Dublin City University, Dublin 9, Ireland.

Tel: +35317007871

Fax: +35317007873

E-mail: tony.killard@dcu.ie

Keywords: Anti-FXa assay, fluorescence, Pefafluor FXa, unfractionated heparin, low molecular weight heparin, danaparoid. 


\begin{abstract}
Fluorogenic assays have many potential advantages over traditional clot-based and chromogenic assays such as the absence of interference from a range of factor deficiencies as well as offering the possibility of assays in platelet rich plasma or whole blood. A fluorogenic anti-factor Xa (anti-FXa) assay has been developed for the determination of heparin-like anticoagulants including unfractionated heparin (UFH), low-molecular weight heparins (LMWHs), namely enoxaparin and tinzaparin, and the synthetic heparinoid danaparoid, in commercial human pooled plasma. The assay was based on the complexation of heparinspiked plasmas with exogenous FXa at a concentration of $4 \mathrm{nM}$ in the presence of $0.9 \mu \mathrm{M}$ of the fluorogenic substrate methylsulfonyl-D-cyclohexylalanyl-glycyl-arginine-7-amino-4methylcoumarin acetate (Pefafluor FXa). Pooled plasma samples were spiked with concentrations of anticoagulants in the range 0 to $1.6 \mathrm{U} / \mathrm{ml}$. The assay was capable of the measurement of UFH and danaparoid in the range $0-1 \mathrm{U} / \mathrm{ml}$, and enoxaparin and tinzaparin in the range $0-0.8 \mathrm{U} / \mathrm{ml}$ and $0-0.6 \mathrm{U} / \mathrm{ml}$, respectively. Assay percentage coefficients of variation were typically below $7 \%$.
\end{abstract}




\section{Introduction}

Antithrombotic drugs are routinely used for a wide range of clinical indications, including the prevention and treatment of venous thromboembolism (VTE) and the acute management of ischaemic heart disease $[1,2]$. Unfractionated heparin (UFH) constitutes the most widely used parenteral antithrombotic therapy [3, 4], and consists of a heterogeneous mixture of negatively-charged glycosaminoglycans derived from either bovine lung, or porcine intestine. UFH exerts its anticoagulant effect primarily through binding to plasma antithrombin (AT) [5]. This binding causes a conformational change in antithrombin, which markedly enhances the ability of antithrombin to specifically inhibit procoagulant factors Xa (FXa) and thrombin (IIa) [1].

Low molecular weight heparins (LMWHs) are synthesised by chemical or enzymatic depolymerisation of heterogeneous UFH glycosaminoglycan chains [1, 6]. LMWHs demonstrate better bioavailability, have significantly longer half-lives compared to UFH [1], and are also associated with reduced incidence of significant complications [7]. Consequently, UFH has been replaced by LMWH as the treatment of choice for many indications. Although the LMWHs share many pharmacodynamic properties, commercial products differ significantly with respect to final molecular weights (4000-7000 Da) [4]. Although the LMWHs all bind to AT, they demonstrate different abilities to enhance inactivation of FXa and/or thrombin (anti-FXa:anti-FIIa ratios ranging from 2:1 to 4:1) [8]. Danaparoid is prepared from bovine and porcine mucosa, and is classed as a low molecular weight heparinoid which has an anti-FXa:anti-IIa ratio of $\geq 22: 1[9]$.

Despite its widespread use, it is well recognized that UFH has a relatively narrow therapeutic window [1]. Consequently, laboratory monitoring and dose-titration of UFH therapy is standard clinical practice. In contrast, because of more predictable pharmacokinetic profiles, LMWH therapy typically requires less laboratory monitoring. A number of different 
laboratory assays have been used to enable adjustment of heparin doses. Most commonly used are clot-based assays in the form of the activated partial thromboplastin time (APTT) [10] and the activated clotting time (ACT) [11]. Nevertheless, it is well established that these assays have a number of important limitations. First, since the APTT is a standard end-point clotting time assay, it can be influenced by many other coagulation variables. For example, the APTT will be prolonged by inherited or acquired coagulation factor deficiencies (including factors XII, XI, X, IX, VIII, V, and II) [8, 12]. Second, more than 300 different laboratory tests are in clinical use to measure the APTT. Previous reports have clearly shown that varying combinations of different commercial reagents and coagulometer machines can result in marked inter-laboratory variability in responsiveness to therapeutic UFH concentrations $[13,14]$. Similarly, although the ACT is widely used to monitor heparin reversal in patients during cardiac surgery, it is also associated with important limitations [15].

Since the APTT is generally insensitive to LMWH, plasma anti-FXa activity monitoring is established as the assay of choice for those patients who require monitoring. In addition, the anti-FXa assay can also be used to monitor UFH levels. Moreover, since the anti-FXa assay generally involves a chromogenic end-point, use of this assay to monitor UFH levels is attractive in that it is not affected by many of the other biologic variable that can interfere with clot-based end-points. While chromogenic assays confer many advantages over standard clot-based assays, there are some drawbacks. The use of chromogenic substrates requires measuring optical density, which renders whole blood and platelet rich plasma samples problematic for colorimetric measurements [16]. Fibrinogen clotting results in turbidity of plasma samples which interferes negatively with absorbance readings [16-18]. Also the lack of a standard anti-FXa chromogenic assay gives rise to significant intervariability between commercially available assays $[13,19]$. 
The potential advantages of fluorogenic assays over chromogenic assays include the ability to use a range of sample types such as platelet poor (PPP), platelet rich (PRP) and whole blood samples, as fluorescence is not as influenced by the opacity of the sample as absorbance [18]. Although fluorogenic assays to assess thrombin generation have been developed, there is accumulating evidence that FXa may represent a better target as it occupies a critical junction in the coagulation cascade [20]. In this study, we have sought to develop a novel plate-based fluorogenic anti-FXa assay that is sensitive to pharmacological concentrations of UFH, LMWHs, and danaparoid. 


\section{Materials and methods}

\subsection{Reagents}

Water (ACS reagent), HEPES (minimum 99.5\% titration) and sodium citrate tribasic dehydrate (ACS reagent, 99.0\%) were all from Sigma-Aldrich (Ireland). Filtered HEPES and sodium citrate solutions had concentrations of $10 \mathrm{mM}(\mathrm{pH} 7.4)$ and $0.1 \mathrm{M}(\mathrm{pH} 5.5)$, respectively. A $100 \mathrm{mM}$ filtered stock solution of $\mathrm{CaCl}_{2}$ was prepared from a $1 \mathrm{M} \mathrm{CaCl}_{2}$ solution (Fluka BioChemika, Switzerland). The fluorogenic substrate methylsulfonyl-Dcyclohexylalanyl-glycyl-arginine-7-amino-4-methylcoumarin acetate (Pefafluor FXa) was purchased from Pentapharm (Basel, Switzerland). It was reconstituted in $1 \mathrm{ml}$ of water having a final concentration of $10 \mathrm{mM}$, aliquoted and stored at $-20^{\circ} \mathrm{C}$ until further use. Dilutions from $10 \mathrm{mM}$ stock solutions down to $10 \mu \mathrm{M}$ were freshly prepared with water when needed. Subsequent dilutions were prepared in $10 \mathrm{mM}$ HEPES. Tubes were covered with aluminum foil to protect from exposure to light. Purified human Factor Xa (FXa) was obtained from HYPHEN BioMed (Neuville-Sur-Oise, France). Tinzaparin (Innohep®) was obtained from LEO Pharma (Ballerup, Denmark). UFH, enoxaparin (Clexane®) and danaparoid (Orgaran $\left.{ }^{\circledR}\right)$ were from Sigma-Aldrich (St Louis, MO), Sanofi-Aventis (Paris, France) and Schering-Plough (Kenilworth, NJ), respectively. Human pooled plasma was purchased from Helena Biosciences Europe (Tyne and Wear, UK). Lyophilised plasma was reconstituted in $1 \mathrm{ml}$ of water and left to stabilize for at least $20 \mathrm{~min}$ at room temperature prior to use.

\subsection{Apparatus and software}

Fluorescence intensities were measured in a microplate reader (Spectrophotometer Infinite M200, Tecan Group Ltd., Switzerland) equipped with a UV Xenon flashlamp. Flat, blackbottom 96-well polystyrol microplates (Nunc ${ }^{\mathrm{TM}}$ FluoroNunc ${ }^{\mathrm{TM}}$ Microplates, Roskilde, Denmark) were used. 


\subsection{Fluorogenic anti-FXa assay}

Measurements were carried out in reconstituted citrated human pooled plasma without the addition of exogenous AT. FXa and Pefafluor FXa were titrated within the range of 0.1$10 \mathrm{nM}$ and $0.1-100 \mu \mathrm{M}\left(K_{\mathrm{m}}=220 \mu \mathrm{M}\right)$, respectively. Each well contained $6.25 \mu \mathrm{l}$ of $100 \mathrm{mM}$ $\mathrm{CaCl}_{2}, 43.75 \mu \mathrm{l}$ of pooled plasma, and $50 \mu \mathrm{l}$ of $\mathrm{FXa}(0.1-10 \mathrm{nM})$. The reaction was started by adding $50 \mu \mathrm{l}$ of Pefafluor FXa fluorogenic substrate (0.1-100 $\mu \mathrm{M})$. Samples within wells were mixed with the aid of orbital shaking at $37^{\circ} \mathrm{C}$ for $30 \mathrm{~s}$. Immediately after shaking, fluorescence measurements were recorded at $37^{\circ} \mathrm{C}$ for $60 \mathrm{~min}$, at $20 \mu$ s intervals. Fluorescence excitation was at $342 \mathrm{~nm}$ and emission was monitored at $440 \mathrm{~nm}$, corresponding to the excitation/emission wavelengths of the 7-amino-4-methylcoumarin (AMC) fluorophore. All the measurements were carried out in triplicate. Following optimization of assay conditions, pooled commercial plasma samples were spiked with pharmacologically relevant concentrations $(0-1.6 \mathrm{U} / \mathrm{ml})$ of therapeutic anticoagulants including UFH, enoxaparin, tinzaparin and danaparoid. In all experiments, reaction progress curves were obtained and analyzed in SigmaPlot 8.0. The reaction rate, which is defined as the change in fluorescence divided by the change in time (i.e., $\mathrm{dF} / \mathrm{dt}$ ), was measured as the linear portion of the fluorescence response profile and plotted versus all different anticoagulant concentrations.

\subsection{Statistical Analysis}

Inter- and intra-assay differences between anticoagulant concentrations were compared using one-way analysis of variance (ANOVA), with subsequent post-hoc analysis performed (Scheffe test) if significance was observed. A result of $(\mathrm{p}<0.05)$ was considered statistically significant. The statistical package SPSS 15.0 was used for data processing and analysis. 


\section{Results}

\subsection{Assay optimization}

In standard anti-FXa assays, excess FXa added to heparinized plasma is inhibited by the heparin-AT complex, and residual FXa activity is assessed using a chromogenic substrate $[19,21]$. Our assay measures the rate of AMC fluorophore released by FXa substrate cleavage, which is inversely dependent upon plasma heparin(oid) concentration. To establish optimal assay concentrations, Pefafluor FXa fluorogenic substrate and FXa were titrated over a range of concentrations. Pefafluor FXa substrate concentration was evaluated within the range of $0.1 \mu \mathrm{M}\left(0.45 \times 10^{-3}\right.$ times $\left.K_{\mathrm{m}}\right)$ to $100 \mu \mathrm{M}\left(0.45\right.$ times $\left.K_{\mathrm{m}}\right)$ with FXa in excess of physiological concentrations (150 pM) [22] at a concentration of $1 \mathrm{nM}$. Pefafluor FXa concentrations were chosen on the basis of working below and around the $K_{\mathrm{m}}$ value to allow differentiation in reaction rates at different anticoagulant concentrations, as the difference in reaction rates at substrate concentrations larger than the $K_{\mathrm{m}}$ is almost negligible. An example of the fluorogenic assay $\mathrm{FXa} /$ substrate titration $(0.8 \mu \mathrm{M}$ substrate and $0.1,1$ and $10 \mathrm{nM} \mathrm{FXa}$ concentrations) can be seen in Fig. 1. The optimized assay is capable of differentiating the concentration of $\mathrm{UFH}$ in commercial human pooled plasma from 0 to $1 \mathrm{U} / \mathrm{ml}$, at a final assay concentration of $4 \mathrm{nM} F X a$ and $0.9 \mu \mathrm{M}$ Pefafluor FXa.

(Figure 1)

\subsection{Evaluation of the anti-FXa fluorogenic assay for the quantitative determination of} anticoagulant dose-response and assay variability

Four heparin drugs were tested using the optimized fluorogenic anti-FXa assay in commercial human pooled plasma. The reaction progress curves were similar for all four drugs in that, as anticoagulant concentration increased, lag times were extended and reaction rates were reduced. This is illustrated in Fig. 2 (inset) which shows the fluorescence profiles of the anti-FXa assay response to UFH. For each type of anticoagulant, the reaction curves 
reached a plateau at approximately the same level (48,000-53,000 AU) independent of anticoagulant concentration. This upper response limit was dictated by the substrate (and thus product) concentration and the upper detection limit of the instrument.

(Figure 2)

The dose-response profile for the assay in UFH was calculated using the linear regions of the fluorescence responses. It can be observed that the assay was capable of the differentiation of UFH concentrations from 0.2 to $1.6 \mathrm{U} / \mathrm{ml}$ at intervals of $0.2 \mathrm{U} / \mathrm{ml}$. The overall response profile was non-linear. It has previously been reported that non-linearity is observed with wide-ranging concentrations of heparin [23] and that the half-life and intensity of the effects of heparin rise disproportionately with increasing heparin dose [4]. Highest assay sensitivity can be observed at lower heparin concentrations $(0-0.6 \mathrm{U} / \mathrm{ml})$ but at the upper range (0.6-1.6 U/ml) the sensitivity of the assay decreased significantly. Response slopes to UFH concentrations at $0.2 \mathrm{U} / \mathrm{ml}$ intervals were statistically different from one another $(\mathrm{p}<0.001)$ up to $1 \mathrm{U} / \mathrm{ml} \mathrm{UFH}$ except for UFH concentrations of $0.6 \mathrm{U} / \mathrm{ml}$ and 0.8 $\mathrm{U} / \mathrm{ml}$ between which there was no statistical difference $(\mathrm{p}=0.441)$.

The anti-FXa assay was tested further on a range of anticoagulant drugs, namely tinzaparin, enoxaparin and danaparoid. The fluorescence response profiles of the fluorogenic anti-FXa assay to tinzaparin and the associated dose-response curve can be seen in Fig. 3. Typically, the responses reached a plateau of around 50,000 - 55,000 AU and lag times increased while the slopes of the linear response region decreased with increasing concentration. In nearly all instances there were statistically significant differences between the slopes of the adjacent drug concentrations $(\mathrm{p}<0.001)$. The resulting dose-response curve was non-linear, with higher sensitivity in the lower tinzaparin range $(0.2-0.6 \mathrm{U} / \mathrm{ml})$. At higher concentrations of the anticoagulant, assay sensitivity again decreased, which was similar to 
that observed for UFH. However, the highest dose tested $(1.6 \mathrm{U} / \mathrm{ml})$ could still be distinguished from the next concentration of $1.4 \mathrm{U} / \mathrm{ml}(\mathrm{p}<0.001)$. LMWHs have been reported as giving a more predictable dose-response than UFH due to better bioavailability at low doses.

(Figure 3)

The effect of enoxaparin was also evaluated using the fluorogenic anti-FXa assay (Fig. 4). Fluorescence response curves showed comparable characteristics to UFH and tinzaparin and again reached a plateau around 50,000 AU. However, the dose-response curve shows that, although the anti-FXa assay had good sensitivity to enoxaparin between 0 and 0.4 $\mathrm{U} / \mathrm{ml}$ and retained moderate sensitivity up to $0.8 \mathrm{U} / \mathrm{ml}$, at concentrations greater than 1.0 $\mathrm{U} / \mathrm{ml}$ the assay showed a significant loss in sensitivity ( $\mathrm{p}>0.05)$.

(Figure 4)

Fig. 5 shows the fluorescence responses from the anti-FXa assay in the presence of danaparoid. Again, similar to earlier results, the fluorescence responses reached a plateau between 45,000-50,000 AU. However, the lag times were more prolonged in the presence of danaparoid than in the presence of UFH. For example, at $0.8 \mathrm{U} / \mathrm{ml}$ danaparoid, the lag time ended at $2000 \mathrm{~s}$ compared to UFH which ended at $500 \mathrm{~s}$. The slopes in the presence of danaparoid were also much lower than for UFH. This is likely due to the more complete inhibition of FXa by danaparoid as a result of its high anti-FXa:anti-FIIa activity ratio of $\geq 22: 1$ [9]. At $1.2 \mathrm{U} / \mathrm{ml}$ the reproducibility also became a significant issue with a $\% \mathrm{CV}$ of $21 \%$. Above this, it was not possible to calculate meaningful slopes. This assay was found to be statistically sensitive to danaparoid up to concentrations of $1 \mathrm{U} / \mathrm{ml}(\mathrm{p}<0.001)$.

(Figure 5) 
Although there was a significant difference between activity at 0 and $0.2 \mathrm{U} / \mathrm{ml}$, there was a near linear response of anti-FXa activity with danaparoid at concentrations of 0.2-1 $\mathrm{U} / \mathrm{ml}\left(\mathrm{R}^{2}=0.9891\right)$ which was not seen with $\mathrm{UFH}$, tinzaparin or enoxaparin indicating a more predictable dose-response relationship. While danaparoid has little effect on standard clotting tests [4] it can be monitored with the anti-FXa fluorogenic assay developed in this study quite reliably.

Also critical to assay performance is the relative standard deviation or percentage coefficient of variation (\%CV). Table 1 summarizes the analytical errors associated with each of the slope measurements, namely the standard deviation and the percentage coefficient of variation for each anticoagulant drug in the anti-FXa assay. CV values for all drugs tested were $<7 \%$ for the plate-based assay (except for a single point at $1.2 \mathrm{U} / \mathrm{ml}$ danaparoid) which are in line with commercially available assays $[24,25]$ and the WHO Expert Committee on Biological Standardization reports. 


\section{Table 1.}

Percentage coefficient of variation (\%CV) and standard deviation (SD) for all anticoagulants tested $(n=3)$.

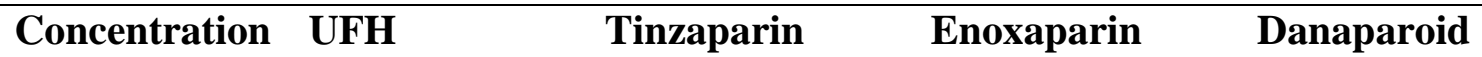

$(\mathrm{U} / \mathbf{m l})$

\begin{tabular}{lllllllll}
\hline & SD & \% CV & SD & \% CV & SD & \% CV & SD & \% CV \\
\hline $\mathbf{0}$ & 7.29 & 6.26 & 5.03 & 3.16 & 1.94 & 1.73 & 1.3 & 0.96 \\
$\mathbf{0 . 2}$ & 1.29 & 1.23 & 1.43 & 1.75 & 1.03 & 1.52 & 2.55 & 4.56 \\
$\mathbf{0 . 4}$ & 2.42 & 3.36 & 2.68 & 4.00 & 0.30 & 0.73 & 1.64 & 3.35 \\
$\mathbf{0 . 6}$ & 0.17 & 0.33 & 1.70 & 4.13 & 0.56 & 0.50 & 2.34 & 6.27 \\
$\mathbf{0 . 8}$ & 2.13 & 4.61 & 2.48 & 6.55 & 1.62 & 5.28 & 1.02 & 4.13 \\
$\mathbf{1 . 0}$ & 1.87 & 4.54 & 0.42 & 1.39 & 10.5 & 3.83 & 0.54 & 3.01 \\
$\mathbf{1 . 2}$ & 0.42 & 1.4 & 1.40 & 5.25 & 0.57 & 2.12 & 4.27 & 20.95 \\
$\mathbf{1 . 4}$ & 1.25 & 4.59 & 0.71 & 5.14 & 0.18 & 0.74 & - & - \\
$\mathbf{1 . 6}$ & 0.83 & 4.19 & 0.44 & 4.13 & 1.11 & 5.52 & - & - \\
\hline
\end{tabular}

\subsection{Comparison of responses of the anti-FXa assay to different drugs}

The inter-assay variability between drugs was also assessed. While the general trend for each drug was similar (Fig. 6), specific differences were observed in the response of each drug. An indication of the inter-assay variation is given by the results for the $0 \mathrm{U} / \mathrm{ml}$ measurements for the four assays. As can be seen in Fig. 6, this value varied from approx. $115 \mathrm{AU} / \mathrm{s}$ to $160 \mathrm{AU} / \mathrm{s}$. This variation could be due to variations in antithrombin activity levels in the control plasma, variations in exogenous Xa activity levels, or other experimental variables such as time and temperature. As a result, the inter-assay variability was $16 \%$. 
(Figure 6)

Statistical analysis of the raw data indicated that concentrations of $0.2,0.4$, and 0.8 $\mathrm{U} / \mathrm{ml}$, for all four drugs tested were significantly different from one another $(\mathrm{p}<0.001)$ with the exception of tinzaparin and UFH at $0.4 \mathrm{U} / \mathrm{ml}(\mathrm{p}=0.78)$. At $0.6 \mathrm{U} / \mathrm{ml}$ and $1 \mathrm{U} / \mathrm{ml}$ the Levene's test was $p=0.020$ and $p=0.032$, respectively. Hence, there were significant differences in the variances and therefore one-way ANOVA could not be applied. At concentrations of 1.2, 1.4, and $1.6 \mathrm{U} / \mathrm{ml}$, statistical analysis showed significant differences between UFH, enoxaparin, and tinzaparin. Danaparoid data was not recorded within this range.

To eliminate differences due to inter-assay variation, ratios of the dose-responses were made against those at $0 \mathrm{U} / \mathrm{ml}$ heparin. Statistical analysis of this normalized data showed specific differences from the raw data. UFH was seen to be distinctive from the LMWHs and danaparoid where it showed comparatively less decrease in assay activity for comparable doses, particularly at lower concentrations. Concentrations of $0.2,0.8,1,1.4$ and $1.6 \mathrm{U} / \mathrm{ml}$ for all four drugs tested were significantly different $(\mathrm{p}<0.001)$. However at 0.8 $\mathrm{U} / \mathrm{ml}$, tinzaparin and enoxaparin were not significantly different $(\mathrm{p}=0.069)$. Also, UFH and enoxaparin were not significantly different at $1.4 \mathrm{U} / \mathrm{ml}(\mathrm{p}=0.064)$ and $1.6 \mathrm{U} / \mathrm{ml}(\mathrm{p}=0.433)$. At concentrations of $0.4 \mathrm{U} / \mathrm{ml}(\mathrm{p}=0.043), 0.6 \mathrm{U} / \mathrm{ml}(\mathrm{p}=0.011)$ and $1.2 \mathrm{U} / \mathrm{ml}(\mathrm{p}=0.004)$ significant differences were identified in the variances, so one-way ANOVA could not be applied.

The responses of all four drugs to the anti-FXa fluorogenic assay can be further compared using the reaction rates (slopes) of the normalized data. UFH at $0.2,0.4,0.8,1.2$, 1.4 and $1.6 \mathrm{U} / \mathrm{ml}$ returned higher reaction rates than both LMWHs and danaparoid. Enoxaparin reaction rates were higher than tinzaparin reaction rates at 0.2, 0.8, 1.4 and 1.6 $\mathrm{U} / \mathrm{ml}$ but at all other concentrations the reaction rates were the same. Danaparoid returned the lowest reaction rates. This pattern could relate to the molecular weights of each drug with 
UFH at 11,393 Da, tinzaparin at 5,866 Da and enoxaparin at 4,371 $\mathrm{Da}$ and danaparoid at a similar molecular weight to LMWHs. At higher molecular weights, greater reaction rates were calculated indicating greater sensitivity of the assay to that particular drug. In addition a trend can be observed between reaction rates and anti-FXa:anti-IIa ratios which also correlates with the pattern observed with molecular weight, e.g.

UFH>tinzaparin>enoxaparin>danaparoid : 1:1>1.9:1>2.7:1 $\geq 22: 1$. A high anti-FXa:anti-FIIa ratio and low molecular weight translates into a lower reaction rate value. 


\section{Discussion}

Injectable drugs such as UFH, LMWHs and associated synthetic heparinoids are widely used and extremely efficacious anticoagulant treatments. However, UFH needs careful monitoring as it suffers significantly from a narrow therapeutic window and the subsequent harmful implications of clotting or bleeding. As already discussed, monitoring of UFH has long relied on clot-based assays (APTT and ACT) which have significant limitations. Furthermore, although LMWHs require less laboratory monitoring due to their predictable pharmacokinetics, monitoring is recommended in populations where pharmacokinetic parameters are altered, including obesity, renal insufficiency, pregnancy, in underweight patients, elderly patients and children [7, 26].

The aim of this study was to develop a novel, reproducible, and sensitive assay using fluorescence to quantify heparin-like drugs in human pooled plasma. Consequently, we measured the effect of four anticoagulants, UFH, enoxaparin, tinzaparin and danaparoid on the fluorogenic anti-FXa assay at anticoagulant concentrations of 0-1.6 U/ml. The intra-assay variability and sensitivity limit was established for each of these four drugs. In addition we investigated the inter-variability of the assay for all drugs, so the assay for UFH was compared with the assay for LMWHs and danaparoid. SPSS statistical analysis proved that there were significant differences in assay sensitivity between drugs.

In the study presented here the anti-FXa assay for UFH was statistically differentiated at intervals of $0.2 \mathrm{U} / \mathrm{ml}$ up to $1 \mathrm{U} / \mathrm{ml}$ and showed excellent reproducibility with CVs below $7 \%$. The anti-FXa assay was also statistically sensitive up to $0.6 \mathrm{U} / \mathrm{ml}$ and $0.8 \mathrm{U} / \mathrm{ml}$ for tinzaparin and enoxaparin, respectively. Assay reproducibility for both LMWHs was excellent with CVs of 0.5-7\%. The anti-FXa:anti-FIIa ratios for enoxaparin and tinzaparin are 2.7:1 and 1.9:1, both exerting a larger inhibitory effect on FXa than thrombin. As has already been stated, LMWHs have less of an effect on ACT and APTT than UFH [6], supporting the 
theory that prolongation of these tests is dependent upon inhibition of thrombin rather than FXa, highlighting the need for an anti-FXa activity test. The use of a single calibration curve for monitoring LMWHs in children has also been suggested [27]. Strong linearity was observed for tinzaparin and enoxaparin calibration curves, with a slight bias towards lower anti-FXa activity with tinzaparin. However, the difference was not significant. With the present fluorogenic anti-FXa assay, the reaction rates for enoxaparin were marginally higher than for tinzaparin, but the differences were not statistically significant as previously reported in the literature [27].

The use of a point of care chromogenic anti-FXa assay for monitoring enoxaparin in patients who have undergone percutaneous coronary intervention (PCI) has been described [28]. The chromogenic ENOX assay described can detect anti-FXa levels of 0.63-1.34 U/ml. However, at lower ranges of anti-FXa activity, the sensitivity of the assay decreases. An analytical range of $0.5-1 \mathrm{U} / \mathrm{ml}$ is appropriate for PCI $[29,30]$ and the fluorogenic assay presented here covers this therapeutic range as well as low dose enoxaparin $(0.2-0.8 \mathrm{U} / \mathrm{ml})$.

Danaparoid has the greatest ratio of anti-FXa:anti-FIIa ( $\geq 22: 1)$ amongst the anticoagulants evaluated and inhibits FXa to a much greater extent than FIIa [4]. The antiFXa assay is considered to be the only adequate assay for monitoring danaparoid. In the present study, it was established that the fluorogenic anti-FXa assay was capable of detection and discrimination of danaparoid up to $1 \mathrm{U} / \mathrm{ml}$ where it demonstrated good reproducibility with CVs of less than $7 \%$, in addition to good linearity between 0.2 and $1 \mathrm{U} / \mathrm{ml}$. Danaparoid cannot be measured using PT, APTT or thrombin clotting time. However, there is a requirement to monitor it in patients with elevated levels of creatinine in serum [4]. A study compared the APTT, ACT and anti-FXa assays for monitoring danaparoid during cardiovascular operations [31]. In spiked samples, APTT and ACT were prolonged in the presence of increasing concentrations of danaparoid. However, in patient samples, both 
assays were insensitive to significant changes in danaparoid levels. The present assay needs to undergo evaluation in patient samples before its usefulness can be fully determined.

In conclusion, a novel fluorogenic anti-FXa assay has been developed which is capable of measuring the impact on the anti-FXa activity of therapeutic concentrations of several heparin-like anticoagulants, namely UFH, tinzaparin, enoxaparin and danaparoid. The assay used $4 \mathrm{nM}$ exogenous FXa and $0.9 \mu \mathrm{M}$ Pefafluor FXa substrate and was performed in commercial human pooled plasmas. This single assay configuration resulted in detection ranges of 0 to $1 \mathrm{U} / \mathrm{ml}$ for $\mathrm{UFH}, 0$ to $0.6 \mathrm{U} / \mathrm{ml}$ tinzaparin, 0 to $0.8 \mathrm{U} / \mathrm{ml}$ enoxaparin, and 0 to 1 $\mathrm{U} / \mathrm{ml}$ for danaparoid with discrimination between doses of $0.2 \mathrm{U} / \mathrm{ml}$ in nearly all cases and typical CVs below $7 \%$. 


\section{Acknowledgements}

This work was supported by Science Foundation Ireland under Grant No. 05/CE3/B754. 


\section{References}

[1] J. Hirsh, T.E. Warkentin, S.G. Shaughnessy, S.S. Anand, J.L. Halperin, R. Raschke, C. Granger, E.M. Ohman, J.E. Dalen, Chest 119 (2001) S64-94.

[2] L.M. Hiebert, S.M. Wice, T. Ping, Biomed. Pharmacother. 58 (2004) 372-80.

[3] R.M. Jay, P. Lui, Tech. Reg. Anesth. Pain Manag. 10 (2006) 30-9.

[4] S. Marsh, B. Appadu, Anaesth. Intensive Care 8 (2007) 209-13.

[5] T.M. Hyers, Semin. Vasc. Surg. 18 (2005) 130-3.

[6] L.A. Linkins, J.A. Julian, J. Rischke, J. Hirsh, J.I. Weitz, Thromb. Res. 107 (2002) 241-4.

[7] T. Baglin, T.W. Barrowcliffe, A. Cohen, M. Greaves, Br. J. Haematol. 133 (2006) 19-34.

[8] S.M. Bates, J.I. Weitz, Circulation 112 (2005) e53-60.

[9] J.W. van der Pijl, F.J. van der Woude, P.H.L.M. Geelhoed-Duijvestijn, M. Frölich, F.J.M. van der Meer, H.H.P.J. Lemkes, L.A. van Es, J. Am. Soc. Nephrol. 8 (1997) 456-62.

[10] M.L. Molinari, G. Zoni, Boll. Chim. Farm. 116 (1977) 149-54.

[11] S.J. Martindale, J.R. Shayevitz, C. D'Errico, J. Cardiothorac. Vasc. Anesth. 10 (1996) 458-63.

[12] S. Kitchen, M. Makris, in: D. O'Shaughnessy, M. Makris, D. Lillicrap (Eds.), Practical Hemostasis and Thrombosis, Blackwell Publishing Ltd., Massachusetts, 2006, pp. 8-17.

[13] S. Kitchen, Br. J. Haematol. 111 (2000) 397-406. 
[14] S.M. Bates, J.I. Weitz, M. Johnston, J. Hirsh, J.S. Ginsberg, Arch. Intern. Med. 161 (2001) 385-91.

[15] J.J. Ferguson, Am. Heart J. 130 (1995) 651-7.

[16] H.C. Hemker, S. Beguin, R. Al Dieri, R. Wagenvoord, S. Nijhuis, P. Giesen, Measuring thrombin activity in whole blood, 2006, WO2006/117246A1.

[17] A.N. Teien, M. Lie, U. Abildgaard, Thromb. Res. 8 (1976) 413-6.

[18] M.K. Ramjee, Anal. Biochem. 277 (2000) 11-8.

[19] V. Ignjatovic, R. Summerhayes, A. Gan, J. Than, A. Chan, A. Cochrane, M. Bennett, S. Horton, F. Shann, G. Lane, M. Ross-Smith, P. Monagle, Thromb. Res. 120 (2007) 34751.

[20] J. Ansell, J. Thromb. Haemost. 5 (2007) 60-4.

[21] A. Tripodi, A. van den Besselaar, Semin. Thromb. Hemost. 35 (2009) 34-41.

[22] J.P. Egea, L.C. Catasús, Stimulators of Factor X activated (FXa) as new topical antihemorrhagic agents, 2007, US2007/0032424 A1.

[23] H.L. Messmore, J. Fareed, J. Kniffin, G. Squillaci, J. Walenga, Ann. N. Y. Acad. Sci. 370 (1981) 785-97.

[24] S. Kitchen, J. Theaker, F.E. Preston, Blood Coagul. Fibrinolysis 11 (2000) 137-44.

[25] D.L. McGlasson, Lab. Med. 36 (2005) 297-9.

[26] N.P. Clark, Thromb. Res. 123 (2008) S58-61. 
[27] J.D. Robertson, L. Brandao, S. Williams, C. Ing, A.K.C. Chan, Thromb. Res. 122 (2008) $867-9$.

[28] S. El Rouby, M. Cohen, A. Gonzales, D. Hoppensteadt, T. Lee, M.L. Zucker, K. Khalid, F.M. LaDuca, J. Fareed, J. Thromb. Thrombolysis 21 (2006) 137-45.

[29] J.P. Collet, G. Montalescot, J.L. Golmard, M.L. Tanguy, A. Ankri, R. Choussat, F. Beygui, G. Drobinski, N. Vignolles, D. Thomas, Am. Heart J. 147 (2004) 655-61.

[30] R. Choussat, G. Montalescot, J.P. Collet, E. Vicaut, A. Ankri, V. Gallois, G. Drobinski, I. Sotirov, D. Thomas, J. Am. Coll. Cardiol. 40 (2002) 1943-50.

[31] S.D. Gitlin, G.M. Deeb, C. Yann, A.H. Schmaier, J. Vasc. Surg. 27 (1998) 568-75. 